\title{
Coaching debates
}

\section{H. N. Wells}

To cite this article: H. N. Wells (1918) Coaching debates, Quarterly Journal of Speech, 4:2, 170-183, DOI: 10.1080/00335631809360665

To link to this article: http://dx.doi.org/10.1080/00335631809360665

曲 Published online: 05 Jun 2009.

Submit your article to this journal

Џ Article views: 7

Q View related articles $\sqsubset$ 


\title{
COACHING DEBATES
}

\section{Purpose ANd Method}

\author{
H. N. WELLS
}

The University of Southern California

BELIEVE that I express the opinion of all experienced teachers of Argumentation and Debate, when I say, that the mind of the college student may be compared to a splendidly equipped workshop, wherein every modern machine and tool is found, but wherein there is found no master hand to use the tools, no directing intelligence to co-relate action, and, what is a far greater need, no will to initiate. Such is the mental content which the college supplies, and it is truly a sumptuous array of mental furniture,-but it is not education.

This condition is well described by Professor William Z. Ripley, of Harvard University, in the preface to his work on "Railway Problems," as follows:

The worst evil of modern academic life ... is that the student may so seldom be called upon to think for himself; - not merely to cram and memorize, to absorb information pre-digested by an instructor, but rather to actively use his reasoning powers in effecting re-combinations of ideas. Mere passive contact for a brief period of life with cultivating influences and high ideals as exemplified in books, general environment, and, it is to be hoped, instructors of the right sort tends to produce the dilettante unless at the same time the mind is constantly invigorated by action.

The invigoration of the mind by action is embraced within the ultimate purpose of debate; but even that salutary office is but a means to the still greater end. The true objective is not mere elegance of polemic style nor proficiency in oral expression, neither is it lucidity of deictic construction nor acuteness of elenctical rejoinder. If the fundamental aim be deemed any one or all of these, then our profession offers no advent to larger things; we are only adding elaborate ornamentation. The mind was intended to be an intellectual and spiritual work-room, where the fine and beautiful ideas are appreciated for their own virtues, to be sure, but cultivated and devoted always to beneficial uses and definite intendments.

1. The true function of Argumentation and Debate is to supply the crucible, wherein the student shall test his knowledge and foment 
his creative impulsions. Here, he must do purposive thinking; he must make vigorous use of every intellectual tool; he must employ every resource of his mind and every grace and power of his personality; all to the end that he may induce other minds to accept his conclusions and act upon them. In other words, it is in debate that the student is forced to use his entire mental equipment to practical purposes.

No generation has so truly needed this peculiar training as that generation which presently is to emerge from our class rooms. We stand at the portals of a new era, in which the problems which have vexed men's minds for ages must be solved. I say that they must be solved, because we have reached that point in economic and political history where civilization cannot escape subversion unless they be solved. Moreover, the world is no longer to be ruled by masters; democracy has come into her own. The demiurgic social swell of the present hour will not stop short of a complete and profound revolution in every activity of human life; democracy must invade society and dominate industry, if it is to be the ruling principle in government. These inevitable transitions create problems which are colossal and appalling, but nevertheless these very students of ours must solve them; and it is our singular task, as instructors in the field of argumentation, to prepare them for this duty.

Whether wisely or not, we cannot know, but men's minds are persistently converging upon that new factor in government, direct legislation. This process forces each individual to decide each complex question of government for himself; there is no escape for anyone. In the new economy the vital necessity will be leaders, men who think correctly to right conclusions and who are endowed with the ability to infuse the minds and enthuse the hearts of other men. Manifestly, neither the mere accumulation of points of knowledge nor the mere attainment of dexterity in speech and subtlety in argument will serve the purpose. Our colleges must develop alert men and women who shall guide the new movement into sane channels, but this can be done only by the introduction of some dynamic element into instruction.

Our profession is called to this high service. We must, therefore, bring to our task that fervor of spirit and vividness of perception which is commensurate with the elevated character of our purpose and with the unique privilege of helping men to discover 
themselves. I know of no miracle so wonderful as the sudden unfolding of a man's mind or the glorious blossoming of a womanly spirit, and I am filled with gratitude that I am permitted to behold these things, and with humility that I should be, in even so small a degree, a contributor to the awakening. With these rich gifts, we salute thee, $O$ America! These are our offerings to the Democracy of the Future! Because democracy stands for the untrammeled right and opportunity to share in thought, to commingle ideas and propulsions, no other department of learning and instruction can rob us of our rich heritage.

2. But, since democracy represents the right and opportunity for mutual expression, it connotes strife. Essentially, it means the inherent and reciprocal right to fight for ideals. It follows, therefore, that the larger conception of the business of the debate coach is the training of men for intellectual combat. Debaters must be fighters. That method of coaching, which develops the best fighter, is the correct system, for, while it is calculated to win debate contests, it is also calculated to excite and hold the interested attention of the general student body for the reason that it is real preparation for intense and useful life. I commend the following method to the consideration of those who believe that debate is a fight.

Most of the foregoing is applicable to both Argumentation and Debate; what I shall say hereafter relates solely to the preparation for intercollegiate debating; and is a radical and deliberate departure from the accepted methods of the class room. The following is a synopsis of the system which has been used by the College of Law of the University of Southern California, for the past six years:

(a) Establish a preliminary squad for rebuttal training.

Rebuttal is the life of debate. It is the heart of the fight. It wins debates. These classes in rebuttal should wrangle (I use the term advisedly) over every conceivable subject of current interest. The coach should enter into the fray, and, while directing thought into the most interesting and legitimate channels, excite by every wile the most spirited interchange of ideas. These classes correspond closely to the preliminary preparation in football, and they serve a similar purpose. They have interested men who never before dreamed of engaging in intercollegiate debate, and these men are often the finest material. Last year, in 
the Law Department, we mustered 105 men from an enrollment of about 700, while the University, with an enrollment of nearly 3,500 , could only enlist some 40-odd men for preliminary foot-ball practice. The rebuttal classes should be started at the commencement of the school-year and continued right up to the "try-out."

(b) The "try-out" should be a test of rebuttal strength.

Construction and organization will develop as the training proceeds; power in rebuttal requires constant practice. Select the rebutters from the "try-outs." Select no teams at the "tryout." Let the "try-out" judges select every contestant who shows promise for the ensuing year, giving no grades; ranking of the contestants should be prohibited. Every man selected is placed in the "Final Squad." A general subject should be announced two or three weeks before the try-out. One hour before the try-out, the Contestants should draw lots for place and side. Then the specific resolution should be announced. This forces extempore speaking and rebuttal. The first speaker on the affirmative should close the try-out, and be judged solely upon his last speech.

(c) The entire "Final Squad" is put to work upon the resolution for the first debate of the season.

The size of the "Final Squad" is immaterial; "the more the merrier." Indeed, the unsuccessful contestants in the try-out should be encouraged to join it, and "buck" the teams, it being understood, however, that the teams are to be selected from the members of the final squad, exclusively.

The side of the resolution elected should never be announced; the squad should develop both sides of it. All material should be carefully preserved for the use of the team, when chosen. Meetings of the squad should be held 3 or 4 times a week, there the free-for-all wrangles of the rebuttal classes should continue, but with more specific direction toward sound analysis. Indeed, this is our method of analysis!! Impossible? Well, just try it once, and see if you miss any of the steps in analysis. You will surely discover one thing, namely, that for perhaps the first time in your experience, you have really considered all the main contentions on both sides of the question and actually are able to deduce the main issues, and this is almost invariably impossible under any other system, where the debaters work alone. The real issues can only be determined when all the possible contentions, both affirmative and negative have been developed. This is beyond the power of any one 
mind, if the debated question be worth-while. The "wrangle" develops surprising and original viewpoints. With 25 to 50 minds concentrating upon a common effort, very little vital material is overlooked, and the question is substantially exhausted in a short time. More real work is accomplished in a month by this method than is ordinarily covered in six, where the members of the teans follow the usual course.

(d) Six reeles prion to the contest, the COACH selects the teams.

Note that the coach selects the teams. No one else is competent to do this. The coach alone is in position to pass upon the qualifications of his men to debate the specific subject, their adaptability to each other and the many intimate factors which enter into the composition of an effective team.

Note, further, that the coach selects teams (a negative and an affirmative), not a team, even when but one side of the resolution is to be debated. The rule is: "Two teams for every debate, and four teams for every simultaneous debate."

(e) The teams must meet and debate the question clear through, includivg rebuttal, $\mathbb{E V E R I} D A Y$ until the day of the debate. The coach must meet with them, and listen to every speech, and every sebuttal.

Now the real work begins. The teams should fight it out no less than some 40 times, before they go upon the debate platform. They should try to overcome each other by every conceivable means during this period, and, if they are held sternly to the program, there is small probability that they will be surprised by any stratagem of their opponents. The debate will grow, day by day, and the final argument will have slight resemblance to the first. The debate will be reconstructed many times, and always with the purpose of avoiding attacks developed by the opposing side, or of launching a telling attack against the opposition. Organization of argument and strategy in its use are developed automi.tically, and the search for new material becomes mighty zealous, in the daily struggle to bring something into the contest, which will bring victory, if only for the once. The fortunes of war shift from side to side; furst, the Affurmative has it, then, the following day, the Negative, reinforced with new material and new argument designed to meet the case of the Affirmative, may win. It is a running fight, never ending until the day of the contest, with a place in the team as the prize to be won, for the men are shifted 
from side to side as they develop strength. Moreover, while the stress has been upon the development of the case, constant and repeated practice has ironed out faults in rhetoric and expression, while complete familiarity with every angle of the debate has given poise and confidence to the speakers.

(f) No team is irrevocably elected; the teams are always fighting for their places.

Every team which debates should fight for the honor with a second team, right up to the date of the debate. Where the debate is simultaneous, four teams should be working up to the date of debate. This gives training to more men, and distributes the benefits further.

(g) The squad is set to work upon the next subject of debate.

The squad is put to work again, immediately following the selection of team, and the above process is repeated. When a team has finished one contest, it should go back into the squad, and contest for place on another team. Last year, we prepared 15 debates, upon 9 totally different subjects.

(h) The first step in the preparation of a debate is the establishment of a theory of the case.

How do we know that we have established the correct theory, before exhaustive research has been made? We don't know, but that is not important. A more pertinent inquiry is this: How can intelligent research be made before a theory is adopted? How will the debater know what to read and what to collect? It is of first importance that $a$ theory be adopted. However, the preliminary "wrangle" is apt to demonstrate the approximately correct theory, particularly if sound criticism on the part of the coach has directed the argument and research into right channels. In any event, the debaters will have a definite plan of operation. Investigation will demonstrate the soundness or fallacy of the theory, or discover a stronger theory, and the work of research is intelligent and purposeful, not divergent and aimless. When the true theory is finally developed, it is usually found to be the correct theory for both affirmative and negative, and the two sides will converge upon it, albeit for the purpose of deducing contrary conclusions.

A consistent theory of the debate forces a consistent argument. It runs like a life-line through the cross-currents of the contest; bearing it in mind the debaters guard their admissions and become exact in their assertions; irrelevant and immaterial matter is excluded, and time conserved. 
(i) Briefs, if necessary, are never drawn until debates are ready for their final weriting.

How can a brief be drawn before the issues are all developed? And, when the issues are clearly demarked, a brief may not be necessary. I do not desire to be misunderstood; I do not undervalue brief-drawing; but the repeated contests of the training period are apt to operate in lieu of many formal processes. Of course, the individual debaters will brief their arguments, perhaps daily, to aid their individual constructions.

May I be permitted to anticipate questions and objections? Here are some which come to my mind:

Do we write our constructive speeches? Yes, nearly always, but we are prepared by the shifting daily contest to throw them away, and extemporize, frequently to the improvement of the debate. Then do we memorize our speeches? Yes, and no. A first affirmative always does, for a proper sense of what is due the audience will demand a carefully prepared and formal opening statement of the case, and valuable time is conserved by the condensation, which is only possible where the speech has been thoroughly prepared in advance. A great advantage is also secured by an opening which is concise and clearly presented.

Let it be remembered that the debaters have passed through a long course of extemporaneous debating, they have been forced daily to meet a new attack. This experience has demonstrated that certain lines of argument and rebuttal are impregnable to attack, or radiate into familiar and welcome fields, if assailed by their opponents. Therefore, the system tends to establish certain definite lines of attack and defense in which the language becomes very familiar through repetition. But this is not analogous to what is ordinarily termed a "memorized" or "set" speech; insofar as it is memorized, it is the resu $t$ of repeated and varied attack and defense in actual combat; it is the flexible fixation growing out of the widest experience in extemporization and the reiterated and successful adaptation of the same line of argument to meet the attack of the opposing team; if "set" in any sense, it is a condensed and corrected substance of argument first extemporized in actual debate, and tested in the cross-fire of actual contest. The pronounced feature of the method is its development of ability to meet every situation with extemporaneous rejoinder. No speech can become "set" unless it be the finished product of the widest sweep of ex- 
temporization, and such a prepared speech or rebuttal is really but the citadel from which the debater is ready to sally forth on an infinite variety of excursions. In other words, the process of training is emphasized extemporization; the result may be a comprehensive and elastic presentation prepared for a foreseen assault. Thus, both resiliency of address and habits of thorough preparation are equally inculcated.

Much has been said in behalf of the value of extempore address, but extempore speaking which is required to meet unforeseen attack because of inadequate preparation, means that training in extempore work has been neglected.

The system presented above has stood the test of six years of intercollegiate coaching. It is calculated to purge the argument of fallacy, for the clash of repeated and varied rebuttal will develop unexpected and original lines of research. Initiative is developed to an extraordinary degree, and the final result is usually a real addition to the solution of the debated problem; other men's ideas, even those of recognized authorities, forming merely the foundation for genuine progression. It is seldom that a case so prepared can be found in any book or speech and often the debater has the gratification which comes from seeing the new thought which he has presented in debate, thereafter introduced to a larger audience in a presidential message or scientific paper. This does not indicate plagiarism on the part of any one, neither does its assertion indicate immodesty or bumptiousness; it merely tends to prove that the process of training discovers the next logical step in the development of the problem, and, further, that the combined effort of many ordinary minds, united in a lively community of purpose, is equal in efficacy and fertility to that of the genius of one great mind. Remember that the result is the product of an intense process of fermentation. Every idea has been subjected to the acid test of boisterous sarcasm and the heckling of irrepressible youth. The proponent of a novel contention must be hardy indeed, if he withstand the assault which descends upon him like an avalanche, albeit, it frequently happens that some seemingly weird or wild idea unfolds the central and determining issue of the subject. You never can tell!!

But does the student have time for this strenuous ordeal? Perhaps the best answer to this inquiry is the scholarship record. It will be sufficient to say that more than one-half of our scholarship 
prize winners are debaters (they get the habit of winning), and that, without exception, the debaters are leaders in scholarship, most of them being members of the honor fraternity for scholarship. And this, notwithstanding the fact that no credit is given for the work done in intercollegiate debate, and that our teams are required to make good all time lost on trips.

Candor requires me to say, however, that a temporary suspension of routine work is usually incident to the three or four weeks preceding a contest, on the part of the men actually engaged in final preparation. But these men speedily recover their stride, and, indeed, seem to have acquired a new vigor from the discipline of the training.

Why not limit the final squad to those who are apt to win places? Why waste time on every man who shows promise? The reasons are numerous, some of them are purely selfish. First, let me repeat: "You never can tell." The ugly duck may grow into an eagle. Then, again, there are other years coming. A man may fail in every try-out until his senior year, but by constant "bucking" of the teams, may become a tremendous force at last. Some minds mature slowly, and suddenly burst into a Volcanic consciousness of power. Every normal person can become a clear thinker and a convincing, cogent speaker,-every normal human being, every one. I don't mean orators, - they, perhaps are born (though I doubt it), but any one can become a successful speaker and debater. I will not believe that worthy ambitions are denied. The existence of a sincere and wholesome desire is its own promise of fulfillment. The fact that a man truly wishes to debate, is the assurance that he may achieve his desire.

Isn't it too severe? Well, life is too severe for some of us. It is a battle, in which we must learn to "endure hardness." Preparation for the struggle is necessary and our instruction is unfaithful if it fail here; and is it not exquisite torture, to create a keen appreciation for the fine things of life, and fail to develop strength to win clean victory? The man who can face his fellow students, ride down the jeers, overwhelm the obstacles they have cunningly devised, tread the devious path through all their traps and stratagems, and compel their respect and even force the acceptance of his judgments, this man is not apt to be denied elsewhere.

This is true preparation for the battle of life. Dullards become emancipated from their mental prisons, and display surprising 
reservoirs of strength and a singular conviction in appeal. No man can consecrate himself so utterly to an idea, and fail to develop hidden powers. He is never the same man again; he has kept high company with regnant, living ideas. He will be a force for good; a leader among men forever after; he can think; he will think; he will be heard also, and always effectively.

Is it necessary to go through the entire debate, with strict enforcement of time-limits, each day? Why require daily repetition of the constructive addresses, especially the first affirmative speech, which is confessedly prepared and memorized? The necessity for absolute familiarity with the treatment which every angle of the debate is to receive is one reason. Thus, even the appearance of conflict in statement is avoided. But repetition affords the opposing team opportunity to administer the most infinite variety of shocks.

But the salient feature of the system is, that its every tendency militates against any address becoming "set." The continued and shifting daily attack compels constant corresponding reconstruction, and even a first affirmative speech may require revision on the last day before the final contest.

One of the questions which Professor O'Neill asked me has been reserved for treatment, for the reason that the reply which I desire to make seems appositely inserted here. In his comment upon my theme, "The Critic's Vote," Professor O'Neill says:

That (the "juryman's vote") is the most perfect scheme for putting a premium on coaching, and the wrong kind of coaching at that, that I have ever heard of. The coach can make out the case and hunt up the evidence, the debater performs the function of a phonograph, and the judge is compelled to vote for the weightiest evidencc, for the work of the coach. This sort of mummery simply isn't debating. When I hear alleged debaters declaiming heavy evidence which has very patently been prepared for them by someone else, and the significance of which the declaimer very evidently does not understand, I vote against him, in favor of some one who has less weighty evidence which he evidently has dug up himself and which he understands and talks about in a direct and intelligent manner. How will Judge Wells vote in such a case?

I will answer by saying that seven years of acute experience in debate coaching has made me very wary of off-hand estimates of the capacities of incipient debaters, and exceedingly reluctant to assume the omniscience, which is requisite to the dogmatic determination of the author or origin of any debate. The young mind, I discover, is astonishingly versatile, and I intend no invidious disrespect for Professor O'Neill's acumen, when I say that I have 
little doubt that he has frequently straffed the wrong man. In another place, but in the same comment, Professor O'Neill says:

The instructor should neither be saved from, nor punished for, his negligence (or his other sins-the italics are mine) by a board of judges called in to judge a student debate.

It seems to me that Professor O'Neill occupied safer ground, when he made the last-quoted statement, than when he undertakes to punish the instructor for his sins of overcoaching or his negligence in permitting his student debaters to enter a contest without an intelligent comprehension of the matter which they present.

Material may be gathered legitimately from so many sources, and what seems to Professor O'Neill to have "very patently been prepared for them by someone else" may have been matter gathered at infinite pains and by means of the most exhaustive research, while the "less weighty evidence which he (the opposing debater) evidently dug up himself" may well be a shining example of taurine superficiality.

No system of judging debates will protect us from the incompetent or unscrupulous coach. It is then too late. It is also an approach from the wrong end of things, to attempt to correct pernicious coaching through the action of a board of judges.

Again, is not the assumption that any judge is competent to decide empirically which sources of uncredited evidence and argument are legitimate and which are illegitimate sufficiently violent to more than offset the rather subtly elaborated list of assumaptions which have been ascribed to the "juryman's vote"? I know of many cases, where debaters have been charged with the sort of thing which Professor O'Neill justly condemns; the charge was sometimes true and sometimes not, but I could not have decided the point, for there often is no distinguishing mark. Suppose both teams offend in this respect, - what will the judge do then?

There is no end to the difficulty, once a judge undertakes to penalize anyone. Who will say where the line shall be drawn? The same kind of trouble arises when we try to equalize matters by the "critic's vote," or other weird systems of judging. The principal argument advanced for deviation from the "juryman's vote" is the unequal nature of contested resolutions. Assuming that the new system does not create inequalities of its own, let us see what this means. We are agreed that "skill in debate," which should be credited, must be valid, -it should be sternly dealt with, 
where it is evasive or in any other manner departs from the paths of dialectical rectitude. But this means, of course, that the debater must stick to the issues and develop his case. In other words, he cannot do more than he could do under the "juryman" system; his limitations and restrictions are precisely the same. How then has he been advantaged, when he finds himself upon the "wrong" side of a lop-sided resolution? Manifestly, he can gain from the new system in only two ways, First, elements of debating skill in which he may have excelled his opponents, and which have already been duly accredited in the effect of the argument (and which contribute mutually to each other through their interplay upon each other, as has been heretofore shown) are again credited, as separate entities. This seems hardly fair, and is based upon the exceedingly doubtful assumption that these elements will yield to separate consideration. The only attempt at concrete illustration, with which I am familiar, is that offered by Professor Sarett, where the elements of debating proficiency confessedly overlap. If they are capable of exact segregation, it is certain that no attempt has thus far been made to demonstrate that alleged fact and explain the process; and I will submit that the burden of the issue, at least, is upon the proponents of the system to do this. If the elements of debating excellence are not capable of exact segregation, then the result must be a piece of guess-work, and cannot be said to represent "definite and sound professional standards," in the language of Professor Sarett.

Second, the unfortunate debater, who finds himself upon the "wrong" side of the resolution, can be further benefited by the "critic's vote," by accrediting outright evasion and jugglery. I am convinced that there is real danger of this, for even Professor $O^{\prime}$ Neill seems to believe that something should be done to compensate the "wrong" side of a patently absurd resolution. But, manifestly, in such a case, the only ability in debate, which it is possible for the unfortunate team to display, must be of the oblique character which we all denounce, for, assuming that the resolution is $100 \%$ absurd, that is, that it is obviously impossible for the unlucky team to prove a valid case, then all argument and every element of debating dexterity must be meretricious in character. If it be $75 \%$ absurd, the difference is only one of degree, while, if it be $25 \%$ absurd, a very clever team may completely hide the specious character of its case, even from an expert judge, who is 
not alert to the strength of the case and the values of the evidence, but is thinking in "terms of ability of contestants." Certainly, in the last hypothetical example, the ratio of probabilities is highly favorable to the success of perverted finesse. This is the normal case of a lop-sided resolution, and, therefore, the danger indicated is very real. No one would expect palpable fraud to be rewarded under any system.

The evils which Professor $O^{\prime}$ Neill seeks to cure are almost wholly the manifestations of faulty training, and the true remedy can only be applied in the system of training. Professor O'Neill's zeal should earn him the commendation of every decent man in our profession, but it requires no concession upon my part to accord him cum laude for loyalty to the highest ideals.

I decline to permit anyone to go before me, however, in due observance of accepted ethics, which I understand requires the coach to restrict his action to vigorous criticism of the worlk actually done by the debaters. Nevertheless, it has always been difficult to understand why evidence and argument, if left severely to the student for development, should be less legitimate, when suggested by the coach, than the same material when gathered from some other source. I find it still more difficult to condeman the industry of the student, whose devotion to his debate leads him to conscript the interest of his neighbors and friends and to beard some industrial or scientific lion in his den to make draft upon their knowledge. I cannot believe that this is intended by the "critic" judge.

The cure is only found in testing everything in the ordeal of battle. After the student debater has endured the sarcasm and biting irony of an impious group of fellow-students, who are never to be convicted of deference to the opinions of the relatives and friends of any fellow who attempts to find a substitute for argument and research, it may be safely assumed that most of the fiddlefaddle will be hazed out of him; he will thereafter understand what he says and why he says it, or he won't say it. No coaching can compare in excellence with the coaching the debaters give each other. The system described above is designed to furnish the opportunity and incentive for this unconscious coaching.

I have said that a due regard for the ethics of our profession has decreed that the coach should offer no material to the debaters. It is less disingenuous to say that $\mathbb{I}$ also observe an increasing reluctance to subject my opinions to the fierce heat of the cross- 
fire I have kindled. Since it is necessary to instil the keenest spirit of critical analysis, it would be as inconsistent to restrain caustic attack upon the opinions of the coach as it would be inconvenient to his aplomb to permit such indignity! Thus, the system automatically adjusts itself to correct standards.

Close contact with glowing young minds is calculated to keep the coach in order. What an amazing privilege we enjoy! To be permitted to inspire the mystic flame of glorious individuality! What an Apocalypse is the unfolding of a mind, the startled look, as it were of wonderment at the beholding of a new-made world, the sudden grasp of the throbbing insinuations of life! What a solemn honor, to hold the key that unlocks the windows of the intelligence! The gate is left ajar, sometimes, and we are allowed a furtive glimpse of things which it is not lawful for man to utter. Verily it is glorious to fight! "He that overcometh shall inherit all things," in that realm, moreover, whereunto "the kings of the earth do bring their glory and honor." 